\title{
Cloning of rat ARHGAP4/C1, a RhoGAP family member expressed in the nervous system that colocalizes with the Golgi complex and microtubules
}

\author{
Victoria C. Foletta $^{\mathrm{a}, 1}$, Fraser D. Brown ${ }^{\mathrm{b}}$, W. Scott Young III ${ }^{\mathrm{a}, *}$ \\ ${ }^{a}$ Section on Neural Gene Expression, The National Institute of Mental Health, National Institutes of Health, Bethesda, MD 20892, USA \\ ${ }^{\mathrm{b}}$ Laboratory of Cellular Biology, The National Heart, Lung and Blood Institute, National Institutes of Health, Bethesda, MD 20892, USA
}

Accepted 27 August 2002

\begin{abstract}
The Rho GTPase family of intracellular molecular switches control multiple cellular functions via the regulation of the actin cytoskeleton. Increasing evidence implicates a critical involvement of these molecules in the nervous system, particularly during neuronal migration and polarity, axon and growth cone guidance, dendritic arborization and synaptic formation. However, the molecules regulating Rho GTPase activities in the nervous system are less known. Here, we present the cloning of rat ARHGAP4, a member of the Rho GTPase activating protein family, and also demonstrate its close linkage to the vasopressin 2 receptor gene. In vitro, recombinant ARHGAP4 stimulated the GTPase activity of three members of Rho GTPases, Rac1, Cdc42 and RhoA. ARHGAP4 mRNA expression was observed in multiple tissues with marked expression throughout the developing and adult nervous systems. On closer analysis of protein levels, ARHGAP4 was significantly restricted to specific regions in the nervous system. These included the stratum lucidem in the CA3 area of the hippocampus, neuronal fibers in the ventral region of the brainstem and striatum, and in the cerebellar granule cells. Subcellularly, endogenous ARHGAP4 expression localized to the Golgi complex and could redistribute to the microtubules, for example during mitosis. In addition, distinct protein expression was observed in the tips of differentiating neurites of PC12 cells. Collectively, these results demonstrate that ARHGAP4 is more widely expressed than previously thought but potentially possesses specialized activity in regulating members of the Rho GTPase family in specific cellular compartments of the nervous system.
\end{abstract}

Published by Elsevier Science B.V.

Theme: Cellular and molecular biology

Topic: Gene structure and function

Keywords: RhoGAP; Nervous system; Golgi network; Microtubulin; cDNA cloning; In situ hybridization histochemistry and immunofluorescence

\section{Introduction}

Rho GTPases are members of the Ras superfamily of small GTP-binding molecules that regulate diverse cellular processes including cell movement, growth and differentiation (reviewed in [54]). Of the multiple Rho members

\footnotetext{
*Corresponding author. Tel.: +1-301-496-8767; fax: +1-301-4021748 .

E-mail address: scott@codon.nih.gov (W. Scott Young III).

${ }^{1}$ Present address: Metabolic Research Unit, School of Health Sciences, Deakin University, Waurn Ponds, VIC 3217, Australia.
}

identified thus far, Rho, Rac and Cdc42 remain the best characterized and are increasingly being shown to mediate morphological changes during neuronal development and synaptic plasticity via the actin cytoskeleton (reviewed in [29]). However, neuronal expression analyses of various Rho GTPases have highlighted their differential expressions indicating that they possess individual roles in specific regions of the brain during its development and differentiation $[34,37,38]$.

Like other GTPases, Rho GTPases cycle between active GTP-bound and inactive GDP-bound states. The control of these states is regulated by three main classes of proteins: 
guanine nucleotide exchange factors (GEFs), guanine nucleotide dissociation inhibitors (GDIs), and GTPase activating proteins (GAPs). GAPs stimulate GTPase activity by enhancing the intrinsic rate of GTP hydrolysis while GEFs promote the exchange of GDP for GTP and GDIs appear to sequester GDP-bound GTPases thereby inhibiting the spontaneous exchange of GDP for GTP.

Numerous Rho GTPase regulatory molecules exist and the neuronal expression of many has been reported; however, the function of these molecules in the brain has been suggested only for a few using cell culture systems $[18,23,26,42,48,56]$ or mutant mice $[7,8]$. The physiological importance of GTPase regulatory proteins in the nervous system is further highlighted by the reports of mutations identified in RhoGAPs, RhoGEFs and RabGDIs resulting in X-linked mental retardation in humans (reviewed in [9]). These mutations likely affect their regulation of target GTPases and/or disrupt alternate signaling pathways in which they are involved. Another human X chromosome-linked putative RhoGAP, C1, has also been identified [52]. The $\mathrm{C} 1$ gene is mapped to a gene-rich region in $\mathrm{Xq} 28$, closely linked to other well-characterized genes such as the vasopressin 2 receptor (V2R) and L1CAM genes [53]. C1 has various aliases including p115, KIAA0131, RGC1 and RhoGAP4. However, new nomenclature classification now terms $\mathrm{C} 1$ as ARHGAP4 (HUGO Gene Nomenclature Committee, http://www.gene.ucl.ac.uk/nomenclature). Preliminary analysis of the human ARHGAP4 protein revealed it is expressed predominantly in hematopoietic cells and that it encodes RhoGAP-like and SH3 domains while the overexpression of ARHGAP4 in mouse fibroblasts decreased actin stress fiber formation [52]. As Rho controls the formation of actin stress fibers and the assembly of focal adhesions [45], it was concluded that human ARHGAP4 could inhibit these Rho activities. The in vivo role of ARHGAP4, however, is still unknown. An individual possessing a microdeletion of the ARHGAP4 and V2R genes presented only with nephrogenic diabetes insipidus, a phenotype purely associated with a lack of functional V2R protein but not with Xlinked mental retardation [46]. Therefore, the loss of ARHGAP4 function appeared to be compensated for by related proteins and hence its physiological function remains to be determined.

In this study, we expand the analysis of the ARHGAP4 gene and the RhoGAP-like protein it encodes. We present the cloning of the rat ortholog and identify multiple domains including GAP, SH3 and FCH domains, and a leucine zipper motif. In vitro biochemical analysis demonstrates strong GAP activity towards Cdc42 and Rac1 in addition to RhoA, and we present the first analysis of its expression in the nervous system. Subcellular localization of endogenous ARHGAP4 in tissue culture cells also identifies its association with the Golgi complex, microtubules and at neurite terminals in differentiating rat PC12 cells.

\section{Materials and methods}

\subsection{Reagents}

Brefeldin A and monoclonal anti- $\beta$-tubulin antibody (clone TUB 2.1) were purchased from Sigma-Aldrich (St. Louis, MO, USA) while the rabbit polyclonal anti-PKC $\epsilon$ antibody was obtained from Santa Cruz Biotechnology (Santa Cruz, CA, USA). Nerve growth factor (NGF) was obtained from Life Technologies, (LTI, Rockville, MD, USA). The rabbit polyclonal anti-ARHGAP4 antibody was raised against a peptide corresponding to 4-20 aa of rat ARHGAP4, conjugated to keyhole limpet hemocyanin and affinity purified. The secondary antibodies, horseradish peroxidase (HRP)-conjugated anti-rabbit or anti-mouse IgG, and Alexa 488 anti-mouse or anti-rat IgG and Alexa 594 anti-rabbit or anti-mouse $\operatorname{IgG}$ were purchased from Amersham Pharmacia (Piscataway, NJ, USA) and Molecular Probes (Portland, OR, USA), respectively.

\subsection{Probes}

The construct used as probe 1 in this study is a rat V2R Pst I/PvuII cDNA fragment (bases 398-911) that is described elsewhere [39]. To generate an antisense cRNA probe that hybridizes to the $3^{\prime}$ untranslated region of the rat ARHGAP4 gene, SP6 RNA polymerase (LTI) was used following digestion of the construct with EcoRI. The cRNA probe, probe 2, used to hybridize to the coding region of the rat ARHGAP4 gene was generated from a partial ARHGAP4 cDNA fragment (nucleotides 10101351) generated by standard PCR using the following oligonucleotides: forward (5'-CCCTCCGAAGCTACACAGCCGCTGAAAGCC) and reverse $\left(5^{\prime}\right.$ CTGATGCCACCACCTCTAGCAGAG). The PCR product was cloned into the pGEM-T vector (Promega, Madison, WI, USA) and to generate a sense or antisense cRNA probe, the plasmid was digested with SacII or NotI and transcribed with SP6 or T7 RNA polymerases, respectively. These probes (probe 1 or probe 2) were used for library screening, northern analysis or in situ hybridization histochemistry where indicated.

\subsection{Cloning and sequencing of rat ARHGAP4 $c D N A$}

To obtain cDNA clones from the complementary strand of the rat V2R gene, probe 1 cRNA probe was labeled with ${ }^{32}$ P-UTP (3000 Ci/mmol, NEN Life Science Products, Boston MA, USA). This probe was used to screen approximately $10^{6}$ bacteriophage clones from a rat spleen $5^{\prime}$ STRETCH cDNA library (Clontech, Palo Alto, CA, USA). The nitrocellulose filters (Schleicher and Schuell, Keene, $\mathrm{NH}$, USA) were pre-hybridized for $18 \mathrm{~h}$ at $65^{\circ} \mathrm{C}$ in $50 \%$ formamide, $1 \times \quad \operatorname{SSPE} \quad(0.15 \quad \mathrm{M} \quad \mathrm{NaCl} / 0.01 \quad \mathrm{M}$ $\mathrm{NaH}_{2} \mathrm{PO}_{4} \cdot \mathrm{H}_{2} \mathrm{O}, \mathrm{pH} 7.4$ ), $10 \%$ dextran sulfate (Sigma, St Louis MO, USA), $5 \times$ Denhardt's solution (0.1\% Ficoll, 
type $400 / 0.1 \%$ polyvinylpyrrolidone $/ 0.1 \%$ bovine serum albumin, fraction V), $250 \mu \mathrm{g} / \mathrm{ml}$ tRNA (LTI), $250 \mu \mathrm{g} / \mathrm{ml}$ fraction XI total yeast RNA (Sigma), $100 \mu \mathrm{g} / \mathrm{ml}$ salmon sperm DNA (LTI), and $0.1 \%$ sodium dodecyl sulfate (SDS). Hybridization was for $24 \mathrm{~h}$ using the same conditions plus the ${ }^{32} \mathrm{P}$-labeled probe 1 at $2 \times 10^{6} \mathrm{cpm} / \mathrm{ml}$. Filters were washed $4 \times 30 \mathrm{~min}$ in $0.1 \times \mathrm{SSC}(0.15 \mathrm{M}$ $\mathrm{NaCl} / 0.015 \mathrm{M}$ sodium citrate, $\mathrm{pH} 7.0$ ) and $0.1 \%$ SDS at $65^{\circ} \mathrm{C}$. cDNA inserts from isolated bacteriophage clones were subcloned into EcoRI restriction sites of pGEM-9z (Promega) and sequenced using the T7 Sequenase version 2.0 DNA kit (USB, Cleveland, OH, USA).

\section{4. $5^{\prime}$ and $3^{\prime}$ RACE}

The 5' and $3^{\prime}$ ends of the rat ARHGAP4 coding region were confirmed by rapid amplification of cDNA ends (RACE) using LTI's 5' RACE, Version 2.0, and 3' RACE System kits according to the manufacturer's instructions. To generate first-strand cDNAs, $1 \mu \mathrm{g}$ of DNase1-treated total RNA isolated from rat thymus was used. For the reverse transcription step in $5^{\prime}$ RACE, a gene-specific primer (5'-CTTCCGGAAACTTTGCTGCTCCGCTGCTGC) was used and a nested primer (5'-CGTCCACTGCGGCTAGTAAAGCGT) plus the kit's anchor primer were used for subsequent PCR amplification. For 3' RACE, a forward gene-specific primer (5'-GGCATCAAGTGACTGGTGGCGAGG) and a nested, forward primer (5'-CATGGGCTAGCATCTACAGCCTCC) were used in conjunction with the kit's universal amplification primers to PCR amplify and reamplify the $3^{\prime}$ RACE product. The 5' and 3' RACE products were cloned into pGEM-T vector (Promega) and sequenced.

\section{5. $p \in M T H-A R H G A P 4$ construction}

The metallothionein promoter-driven eukaryotic expression vector with a 12-aa PKC€ epitope tag (p€MTH, [36]) was used to overexpress ARHGAP4 in mammalian systems. The p€MTH-ARHGAP4 plasmid was generated following cloning the PCR product of the rat ARHGAP4 coding region into the $X h o \mathrm{I}$ and $M l u \mathrm{I}$ restriction sites. The PCR product was synthesized using the rat ARHGAP cDNA as template and the forward $\left(5^{\prime}\right.$ CTAGCTCGAGATGGCGGCGCACGGGAAGTTGCGG) and reverse (5' GCTAACGCGTGACTGGCTTGCGAGTTGAATCTGG) primers, which included the XhoI and $M l u I$ restriction sites within the sequences, respectively.

\subsection{Cell culture and transfection}

Rat NRK and PC12 cells were obtained from American Type Culture Collection (Manassass, VA, USA). NRK cells were maintained in Dulbecco's modified Eagle's medium/ $10 \%$ fetal bovine serum and RPMI 1640/10\% horse serum $/ 5 \%$ fetal bovine serum, respectively. Transient transfections were performed using Lipofectamine 2000 (LTI) according to the manufacturer's recommendations. To induce the expression of $\mathrm{p} \in \mathrm{MTH}-\mathrm{ARHGAP} 4$ following transfection of NIH 3 T3 cells, $75 \mu \mathrm{M}$ zinc acetate was added overnight prior to harvesting.

\subsection{Animals and tissue preparation}

For Northern and Western blots, and in situ hybridization histochemical analyses, tissues from embryonic and adult male and female Sprague-Dawley rats (Taconic Farms, Germantown, NY, USA) were removed following $\mathrm{CO}_{2}$ asphyxiation, rapidly frozen on crushed dry ice and stored at $-80{ }^{\circ} \mathrm{C}$. For immunohistochemical analysis, adult rats were perfused with $4 \%$ paraformaldehyde (PFA), $\mathrm{pH}$ 7.2 , and $15 \%$ picric acid in phosphate buffered saline (PBS). Tissues were removed and washed at $4{ }^{\circ} \mathrm{C}$ in graded sucrose solutions that included $5 \%$ sucrose $/ 0.9 \%$ saline and $10 \%$ sucrose $/ 0.9 \%$ saline for $1 \mathrm{~h}$ each and then in $15 \%$ sucrose $/ 0.9 \%$ saline overnight.

\subsection{Northern blot analysis}

Total RNA was isolated from frozen rat tissues using TRIzol (LTI). Ten micrograms of total RNA was sizefractionated on a 1.2\%-agarose/formaldehyde gel and electroblotted to GeneScreen (NEN Life Science Products). Prehybridization and hybridization conditions were as described above for the cDNA library screen.

\subsection{Western blot analysis}

Rat tissues were homogenized and cultured cells were lysed on ice in a standard lysis buffer containing phosphatase inhibitors $\left(10 \mathrm{mM} \mathrm{NaF}, 1 \mathrm{mM} \mathrm{Na} \mathrm{VO}_{4}\right.$, and $1 \mathrm{mM}$ sodium pyrophosphate) and protease inhibitors (2 $\mathrm{mM}$ leupeptin, $2 \mathrm{mM}$ aprotinin, $10 \mu \mathrm{g} / \mathrm{ml}$ bestatin, $400 \mu \mathrm{g} / \mathrm{ml}$ AEBSF, $1 \mu \mathrm{g} / \mathrm{ml}$ pepstatin, and $50 \mu \mathrm{g} / \mathrm{ml}$ antipain [Calbiochem]). Whole cell lysates were collected and protein concentrations were determined using a BCA protein assay kit (Pierce, Rockford, IL, USA). To obtain soluble and insoluble fractions, protein extracts were centrifuged using a TLA-120.1 rotor (Optima Max ultracentrifuge, Beckman Coulter, CA, USA) at 100,000 $g$ for $40 \mathrm{~min}$ at room temperature. Protein fractions were resolved by SDS-PAGE and transferred to Immobilon-P membranes (Millipore). Immunoblotting involved blocking in $0.2 \%$ I-Block (Tropix, Bedford, MA, USA) and $0.1 \%$ Tween-20 in PBS followed by incubation with 1:1000 dilution of normal goat serum (NGS, Vector, Burlingame, CA, USA) and 1:500 dilution of rabbit polyclonal antiARHGAP4 or anti-PKC $\epsilon$ antibodies for $1 \mathrm{~h}$. Blots were washed for $15 \mathrm{~min}, 3$ times, in $5 \times \mathrm{PBS} / 0.1 \%$ Tween-20 and incubated in the I-Block solution with dilutions of 1:4000 HRP-conjugated anti-rabbit IgG secondary antibody for $1 \mathrm{~h}$. Blots were washed for $30 \mathrm{~min}, 3$ times, in 
$1 \times$ PBS $/ 0.1 \%$ Tween 20 before developing in Chemiluminescence Reagent Plus (NEN).

\subsection{In situ hybridization histochemistry}

In situ hybridization histochemistry and autoradiography was performed on $12 \mu \mathrm{m}$ fresh frozen tissue sections as described previously [6]. cRNA transcripts generated from probe 1 or probe 2 constructs were labeled with ${ }^{35} \mathrm{~S}$-UTP (1250 Ci/mmol, NEN). The sections were initially exposed to Fuji Bas2000 PhosphorImage plates (Fuji Medical Systems, Stamford, CT, USA) before dipping in Ilford K.5D emulsion (Polysciences, Warrington, PA, USA) containing $300 \mathrm{mM}$ ammonium acetate for up to 4 months. Following development in Kodak Rapid Fix (Eastman Kodak, Rochester, NY, USA), the slides were counterstained in $0.1 \%$ toludine blue. Images were photographed using a SenSys-KF1401E CCD camera (Photometrics, Tuscon, AZ, USA).

\subsection{Immunohistochemistry and immunofluorescence}

Immunohistochemistry was performed on $12 \mu \mathrm{m}$ frozen sections from adult rat brain as outlined previously [57] using anti-ARHGAP4 antibody at a 1:1000 dilution. For immunofluorescent staining of NRK and PC12 cells, $10^{5}$ cells were seeded onto circular glass coverslips in 12-well plates. For PC12 cells, the coverslips were coated with rat collagen prior to seeding. NRK cells the next day or PC12 cells following 2 days of treatment with $100 \mathrm{ng} / \mathrm{ml} \mathrm{NGF}$, were fixed in 2\% PFA/PBS, pH7.2, for $20 \mathrm{~min}$ and blocked for $30 \mathrm{~min}$ in $10 \% \mathrm{FCS} / \mathrm{PBS}$. The primary antibodies, anti-ARHGAP4 or mouse monoclonal anti- $\beta$ tubulin were used at $1: 300$ or $1: 200$ diluted in $10 \%$ FCS/PBS plus $0.2 \%$ saponin (Sigma), respectively. The cells were incubated for $1 \mathrm{~h}$, washed for $5 \mathrm{~min}, 3$ times, in $10 \%$ FCS/PBS and then probed for $1 \mathrm{~h}$ with Alexa secondary antibodies diluted 1:750 in 10\% FCS/PBS/ $0.2 \%$ saponin. Following three 5-min washes in PBS the coverslips were mounted in Fluoromount $G$ (Electron Microscopy Services, Washington, PA, USA). Fluorescent images were acquired using a SenSys-KF1401E CCD camera.

\subsection{Expression and purification of recombinant proteins}

The rat ARHGAP4 GAP domain plus flanking regions (474-743 aa) was generated by PCR using forward (5' TCGG AATT CCT GCAG GCCA AGCATG AAAAGCTC CAG) and reverse (5'-ACAGAATTCGCTCTCCAACTGGCCATCCCCCAGGCAG) primers containing EcoRI sites. PCR products were cloned in-frame into the EcoRI site of the bacterial expression vector pGEX-2T $128 / 129$. The expression plasmids were maintained in the $E$. coli strain, XL1-Blue (Stratagene), but were expressed in BL21
(DE3) cells (Novagen, Madison, WI, USA). The induction and purification of the recombinant proteins (ARHGAP4GAP, RhoA, Rac1 and Cdc42) were carried out using the glutathione S-transferase Gene Fusion System (Pharmacia Biotech, Piscataway, NJ, USA) as described by the manufacturer.

\subsection{Filter-binding assay of GTPase activity}

The measurement of ARHGAP4-GAP activity was performed according to Settleman and Foster [47] using filter binding to assay the reaction products. Each recombinant GTPase protein (50 ng) was assayed with equimolar amounts or incremental quantities of recombinant ARHGAP4-GAP protein in time course or protein dependence assays, respectively.

\section{Results}

\subsection{Cloning of the rat ARHGAP4 cDNA}

Previous work involving in situ hybridization histochemical analysis of the rat V2R gene expression revealed the expression of an antisense mRNA transcript in the central nervous systems of embryonic rats [16]. The control sense riboprobe (probe 1, Fig. 1A) used in this study detected an unknown, antisense mRNA species transcribed from the complementary DNA strand of the V2R gene. Northern analysis of total RNA extracted from rat embryonic and adult brain regions using probe 1 revealed the expression of an $11-\mathrm{kb}$ transcript in most brain regions (Fig. 1B) with greater expression evident in spleen and thymus (data not shown). As the rat V2R gene is expressed specifically in the kidney as a $2-\mathrm{kb}$ transcript [28], the expression of the 11-kb transcript suggested the presence of an alternate gene in close proximity to the rat V2R gene. To identify the origin of this transcript, a rat spleen cDNA library was screened with probe 1 in a successful attempt to isolate potential cDNAs specifically expressed from the opposite DNA strand to that of the V2R gene. A 6.4-kb cDNA clone was obtained and sequenced. The clone contained a $2.9-\mathrm{kb}$ open reading frame (ORF), $3^{\prime}$ to that of the V2R coding region (Fig. 1A). Nucleotide BLAST search (http://www.ncbi.nlm.nih.gov/BLAST) of the ORF sequence revealed high homology to the cDNA sequence of the human gene, ARHGAP4, also known as C1, RGC1, RhoGAP4 and KIAA0131 ${ }^{2}$. The p115 human ARHGAP4 protein, originally known as $\mathrm{C} 1$, was identified by sequence analysis as a RhoGAP and was highly expressed in hematopoietic cells [52]. On the human $\mathrm{X}$

\footnotetext{
${ }^{2}$ GenBank $=$ GenBank Accession Numbers NM 001666 (human ARHGAP4), X78817 (C1), XM 013052 (RGC), U52112 (RhoGAP4), D50921 (KIAA0131), O43295 (KIAA0411), and U52112 (human Xq28 V2R/ARHGAP4 locus).
} 
A

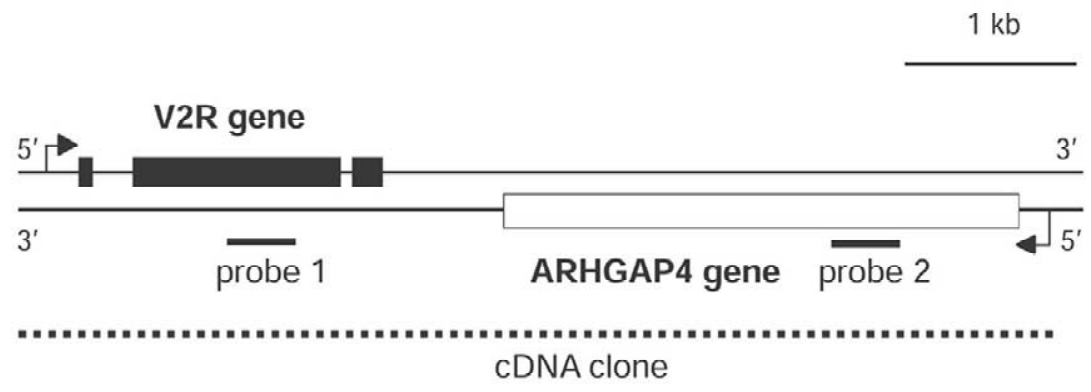

\section{B Probe 1:}

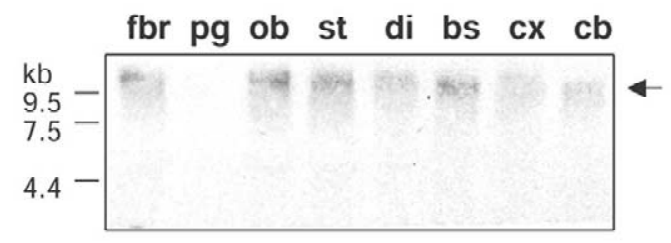

C Probe 2:

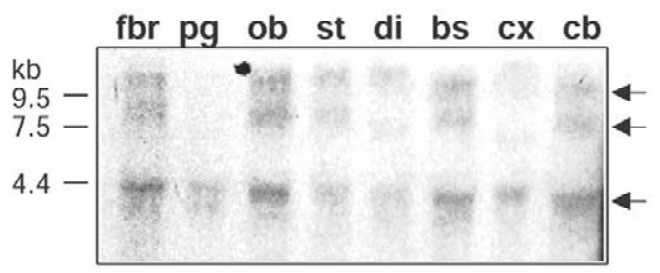

D Probe 2:

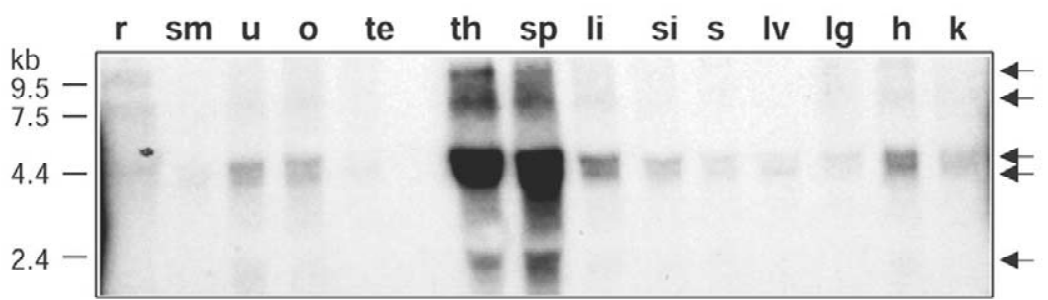

Fig. 1. The rat ARHGAP4 and V2 gene loci and tissue distribution of ARHGAP4 gene expression. (A), A schematic representation of the rat ARHGAP4 gene's proximity to the V2R gene. The coding region of the ARHGAP4 gene (open box) lies $3^{\prime}$ to the rat V2R coding region (black boxes) on opposite DNA strands. The transcriptional/translational orientations of the genes are indicated (arrows). Probes 1 and 2 (bars) represent the positions of the antisense riboprobes used for hybridization to the $3^{\prime}$ and 5' regions of ARHGAP4 transcripts, respectively. Probe 1 was used to isolate the $6.4 \mathrm{~kb}$ cDNA clone containing the rat ARHGAP4 cDNA (dotted line). (B), Northern blot analysis of ARHGAP4 gene expression in regions of fetal and adult rat brain using probe 1. (C) and (D), Northern blot analysis in brain and other tissues using probe 2. Arrows in B-D indicate the position of transcripts. Abbreviations: fbr, fetal brain (E18); pg, pituitary gland; ob, olfactory bulb; st, striatum; di, diencephalon; bs, brainstem, cx, cortex; cb, cerebellum; r, retina; sm, skeletal muscle; u, uterus; o, ovary; te, testis; th, thymus; sp, spleen; li, large intestine; si, small intestine; s, stomach; lv, liver; lg, lung; h, heart; k, kidney.

chromosome, the ARHGAP4 gene is found immediately adjacent and oriented towards the V2R gene on opposite DNA strands at Xq28 [53], similar to what we observed in the rat. The nucleotide sequence of the rat ARHGAP4 gene is $3205 \mathrm{bp}$, confirmed by $5^{\prime}$ - and $3^{\prime}$-RACE analysis. Within the nucleotide sequence is an ORF of $2898 \mathrm{bp}$ 


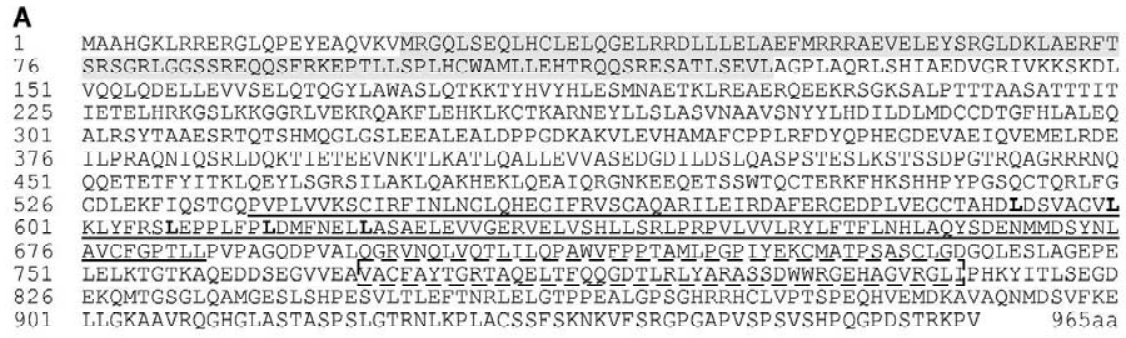

B

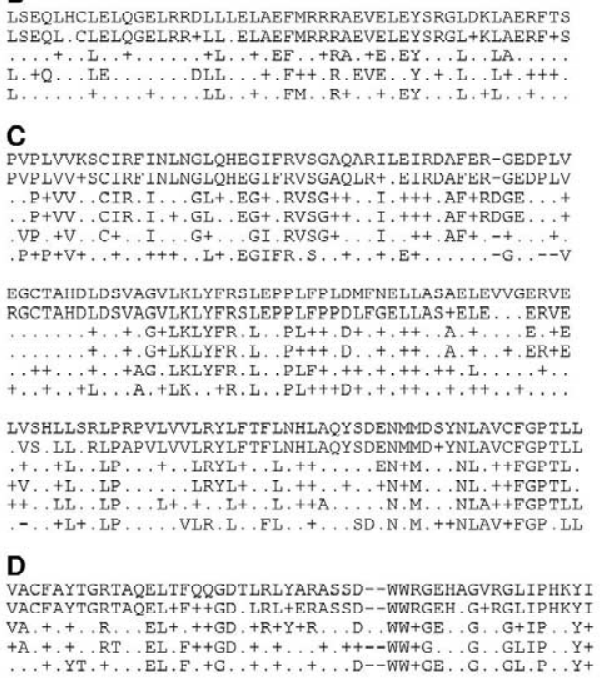

\begin{tabular}{|c|c|c|}
\hline $\begin{array}{l}\text { Amino } \\
\text { Acids }\end{array}$ & $\begin{array}{l}\text { Protein } \\
\text { name }\end{array}$ & $\begin{array}{l}\text { GenBank } \\
\text { aceess. no. }\end{array}$ \\
\hline $\begin{array}{l}28-76 \\
28-76\end{array}$ & $\begin{array}{l}\text { rat ARHGAP4 } \\
\text { human ARHGAP4 }\end{array}$ & $\begin{array}{l}\text { AF401635 } \\
\text { NM_ } 001666\end{array}$ \\
\hline $10-57$ & cdc15 & X86179 \\
\hline $\begin{array}{l}7.53 \\
7.53\end{array}$ & $\begin{array}{l}\text { CPP-4 } \\
\text { FER }\end{array}$ & $\begin{array}{l}\text { ANO00414 } \\
\text { NM } 005264\end{array}$ \\
\hline $538-585$ & rat ARHGAP4 & AF401635 \\
\hline $\begin{array}{l}519-566 \\
155-203\end{array}$ & human ARHGAP4 & NM_001666 \\
\hline $\begin{array}{l}155-203 \\
280937\end{array}$ & n-chimerin & $\begin{array}{r}X 67250 \\
\end{array}$ \\
\hline $1066-111$ & p-chimerin & $\begin{array}{l}028926 \\
\times 0056\end{array}$ \\
\hline $\begin{array}{l}106-1111 \\
256-302\end{array}$ & $\begin{array}{l}\text { of } \\
\text { p50 rhoGAP }\end{array}$ & Z23024 \\
\hline $586-634$ & rat ARHGAP4 & AF401635 \\
\hline $\begin{array}{l}567-615 \\
204-252\end{array}$ & $\begin{array}{l}\text { human ARHGAP4 } \\
\text { n-chimeriin }\end{array}$ & $\begin{array}{l}\text { NM } 0016 \\
\text { X67750 }\end{array}$ \\
\hline $\begin{array}{l}204-338-386 \\
3386\end{array}$ & $\begin{array}{l}\text { n-chumerm } \\
\beta \text {-chimerin }\end{array}$ & $\begin{array}{r}x 67250 \\
\text { U28926 }\end{array}$ \\
\hline $1114-1162$ & bcr & X02596 \\
\hline $303-351$ & p50 rloGAP & Z23024 \\
\hline $\begin{array}{l}635-684 \\
616-665\end{array}$ & $\begin{array}{l}\text { rat ARHGAP4 } \\
\text { human ARHGAP4 }\end{array}$ & AF401635 \\
\hline 253-302 & $\begin{array}{l}\text { humanan ARHAGAF } \\
\text { n-chimerin }\end{array}$ & $\begin{array}{l}\text { NM_000600 } \\
\text { X67250 }\end{array}$ \\
\hline $387-436$ & $\beta$-chimerin & $\begin{array}{l}\text { U28926 } \\
\text { X } 00506\end{array}$ \\
\hline $\begin{array}{l}11032-401 \\
352\end{array}$ & p50 rhoGAP & Z23024 \\
\hline 77 & rat ARHGAP4 & AF401635 \\
\hline $2-8$ & $\begin{array}{l}\text { human } \\
\text { vav2 }\end{array}$ & $\begin{array}{l}\text { NM } 001 \\
\text { S76992 }\end{array}$ \\
\hline $61-509$ & $\begin{array}{l}\text { OSF-1 } \\
\text { SH3P17 }\end{array}$ & $\begin{array}{l}\text { U6371717 } \\
\text { U61166 }\end{array}$ \\
\hline
\end{tabular}

Fig. 2. Rat ARHGAP4 protein sequence and domain alignments. (A) Amino acid sequence of rat ARHGAP4 with the FCH (shaded region), GAP (underlined), and SH3 (dashed box) domains indicated and the leucine zipper motif highlighted in bold. Rat ARHGAP4 FCH (B), GAP (C) and SH3 (D) domain amino acid alignments with related mammalian proteins. Nonconserved residues (.), homologous or conserved residues $(+)$ and gaps in sequence $(-)$ are indicated. The right-hand panels indicate the region of amino acid residues that the domains span across, the specific protein and its corresponding GenBank accession number.

beginning at nucleotide 109 and finishing at nucleotide $3006^{3}$. Further Northern blot analysis using a riboprobe that hybridizes to the sense strand of rat ARHGAP4 (probe 2, Fig. 1A) again revealed ARHGAP4 gene expression in brain, spleen and thymus and in other rat tissues; however, multiple transcripts in addition to the $11 \mathrm{~kb}$ species were detected (Fig. 1C-D). Four other transcripts at the sizes of 7, 3.8, 4 and $2 \mathrm{~kb}$ were evident in spleen and thymus where the 3.8 and $4 \mathrm{~kb}$ species were more highly expressed. In brain, however, the 3.8 and $2 \mathrm{~kb}$ transcripts were not clearly evident suggesting tissue-specific differences in ARHGAP4 expression (Fig. 1C). Northern blot analysis of polyadenylated RNAs extracted from rat brain and spleen tissues also retained a similar pattern of ARHGAP4 expression (data not shown).

\subsection{Amino acid sequence analysis}

The coding region of rat ARHGAP4 putatively encodes

\footnotetext{
${ }^{3}$ The nucleotide sequence for the rat ARHGAP4 cDNA has been deposited in the GenBank database under GenBank Accession Number (AF401635).
}

a 965-aa protein (Fig. 2A) with a calculated molecular mass of $107 \mathrm{kDa}$. A BLAST search of the swissprot database revealed rat ARHGAP4 as having $71 \%$ protein identity with the human ARHGAP4 protein and 40\% identity with the hypothetical protein KIAA0411 ${ }^{2}$. As in the human ARHGAP4 protein sequence, a RhoGAP domain (538-684 aa) and a SH3 domain (771-819 aa) are present in the rat ARHGAP4 amino acid sequence (Fig. 2A). The rat ARHGAP4 GAP domain has greatest protein identity $(22-28 \%)$ to the GAP domains of various mammalian members of the RhoGAP family including the $\beta$-and N-chimerins, Bcr, and p50 RhoGAP (Fig. 2C), and the SH3-binding protein 3BP-1, ARHGAP6, and the myosin heavy chain proteins (data not shown). BLAST search also revealed between 32 and $39 \%$ protein identity between the rat ARHGAP4 SH3 domain and other mammalian SH3-containing signaling molecules including Vav2, osteoclast stimulating factor-1, and SH3P17 (Fig. 2D), and to various adaptor molecules and protein tyrosine kinases (data not shown). ScanProsite (http://www.expasy.ch) and BLAST Conserved Domain searches revealed additional domains and features in the rat ARHGAP4 protein sequence. These include a leucine zipper motif, 
which contains a heptad repeat of 5 leucine residues spaced 7 aa apart within the GAP domain (593-621 aa; Fig. 2A) and functions to form dimeric complexes [25]. Indeed, mammalian two-hybrid analysis in monkey CV1 cells using a method described previously [30] confirmed the leucine zipper of the rat and human ARHGAP4 to form homodimers (data not shown). A FER/CIP-4 homology (FCH) domain is also evident in the $\mathrm{NH}_{2}$-terminal region of rat ARHGAP4 (24-125 aa; Fig. 2A). The FCH domain was previously identified in the $\mathrm{Cdc} 42$-interacting protein4 (CIP-4) and other proteins including the non-receptor tyrosine kinase FER, the fission yeast cytokinesis regulator cdc15, and also human ARHGAP4 [2]. The extent of rat ARHGAP4's protein sequence identity with the $\mathrm{FCH}$ domains of CIP-4, cdc15 and FER proteins is presented in Fig. 2B.

\subsection{In vitro $G A P$ assay}

To test whether the GAP domain of ARHGAP4 is capable of biochemical activity, its effect on the GTPase activities of RhoA, Rac1 and $\mathrm{Cdc} 42$ was analyzed in vitro.
Using purified, recombinant proteins, the ARHGAP4-GAP domain was found to promote the hydrolysis of bound GTP for each GTPase. Although each GTPase has intrinsic hydrolysis activity, in the presence of ARHGAP4-GAP this activity was markedly increased (Fig. 3A-C), particularly for $\mathrm{Cdc} 42$ and Rac1. Further analysis revealed that approximately 10- and 4-fold less ARHGAP4-GAP protein was required for $\mathrm{Rac} 1$ and $\mathrm{Cdc} 42$, respectively, to reach a $50 \%$ loss of bound GTP compared to RhoA following a 5-min incubation (Fig. 3D).

\subsection{In situ hybridization histochemistry analyses}

Previous analysis of human ARHGAP4 revealed it to be predominantly expressed in hematopoietic tissues and cell lines [52]. As our Northern and Western data of the rat ARHGAP4 gene reveals expression in a variety of tissues in addition to spleen and thymus, we extended the analysis of rat ARHGAP4 mRNA and protein expression by examining the nervous system. Probe 2, an antisense riboprobe that hybridizes to the 5' region of rat ARHGAP4
A

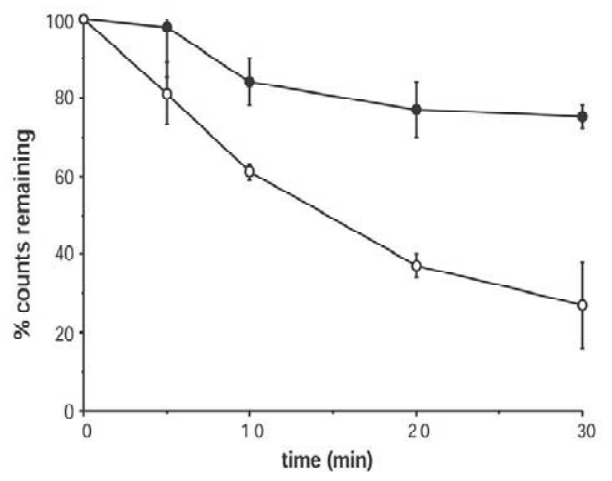

C

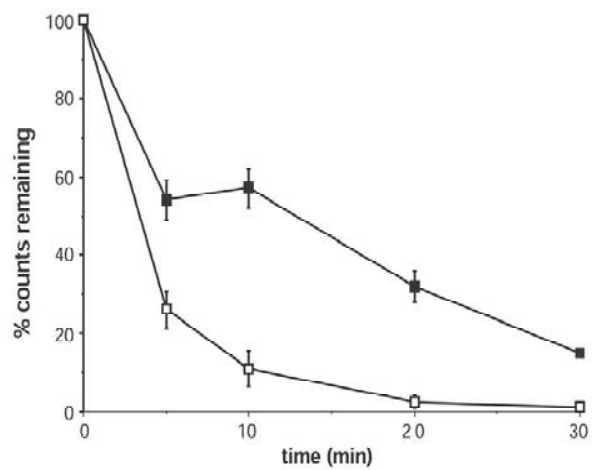

B

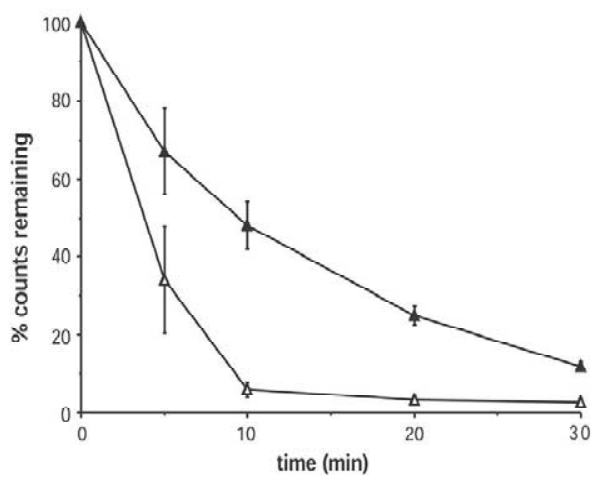

D

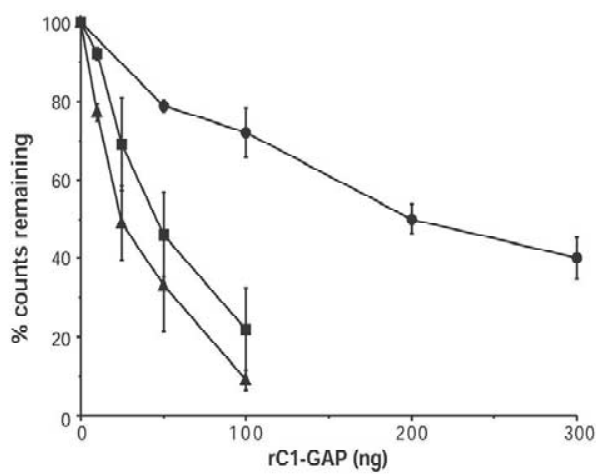

Fig. 3. In vitro GAP activity of rat ARHGAP4. Time dependence and protein concentration effects of the ARHGAP4 GAP domain on the activation of Rho GTPases in filter binding assays. Fifty nanograms of $\gamma_{-}{ }^{32} \mathrm{P}$ GTP-bound RhoA (A), Rac1 (B), and Cdc42 (C) were assayed for the hydrolysis of GTP in the absence or presence of equimolar amounts of the rat ARHGAP4-GAP protein or in the presence of increasing amounts of ARHGAP4-GAP protein following a 5-min incubation (D). Symbols: RhoA (filled circle); RhoA+ARHGAP4-GAP (open circle); Rac1 (filled triangle); Rac1+ARHGAP4-GAP (open triangle); Cdc42 (filled square); Cdc42+ARHGAP4-GAP (open square). The data are representative of the mean \pm S.D. from three independent experiments. 
(Fig. 1A), revealed ARHGAP4 gene expression as early as embryonic day 15 (E15) throughout the developing central nervous system (CNS) using in situ hybridization histochemistry (not shown). By E18, ARHGAP4 mRNA was also evident in the developing thymus (Fig. 4A), which clearly increases by E21 (Fig. 4C). The expression of ARHGAP4 mRNA remained in the CNS and thymus during later embryonic and postnatal stages while in the nervous system expression became more prominent in the differentiating cortex and olfactory bulb (Fig. 4C-D). In the adult rat, ARHGAP4 gene expression remained throughout most regions of the rat brain (Fig. 5A). At higher magnification, mRNA was revealed in various neuronal cell populations including the granule cells of the cerebellum, olfactory bulb and dentate gyrus, and in neurons of the hippocampal pyramidal cell layer, pontine nuclei and tubercle (Fig. 5B and $D-G)$. No significant labeling was evident with the sense control riboprobes (Figs. 4B, E and 5A', C).

\subsection{Endogenous subcellular localization}

We next examined the endogenous cellular localisation of ARHGAP4 in rat NRK kidney epithelial cells and PC12 cells using an affinity-purified rabbit polyclonal antibody raised against a peptide derived from the $\mathrm{NH}_{2}$-terminus of the rat ARHGAP4 protein. No specific labeling was observed following staining with the rabbit pre-immune serum (Fig. 6C). In contrast, immunostaining with the anti-ARHGAP4 antibody revealed prominent perinuclear distribution of rat ARHGAP4 (Fig. 6A). Cells transfected with a plasmid encoding the $\beta 1,4$-galactosyltransferase, a trans-Golgi-specific enzyme fused with the green fluorescent protein (Fig. 6B; [11]), revealed an identical expression pattern with rat ARHGAP4 protein confirming rat ARHGAP4's localization at the Golgi complex. To further characterize ARHGAP4's association with the Golgi complex, NRK cells were treated with the brefeldin A (BFA), a
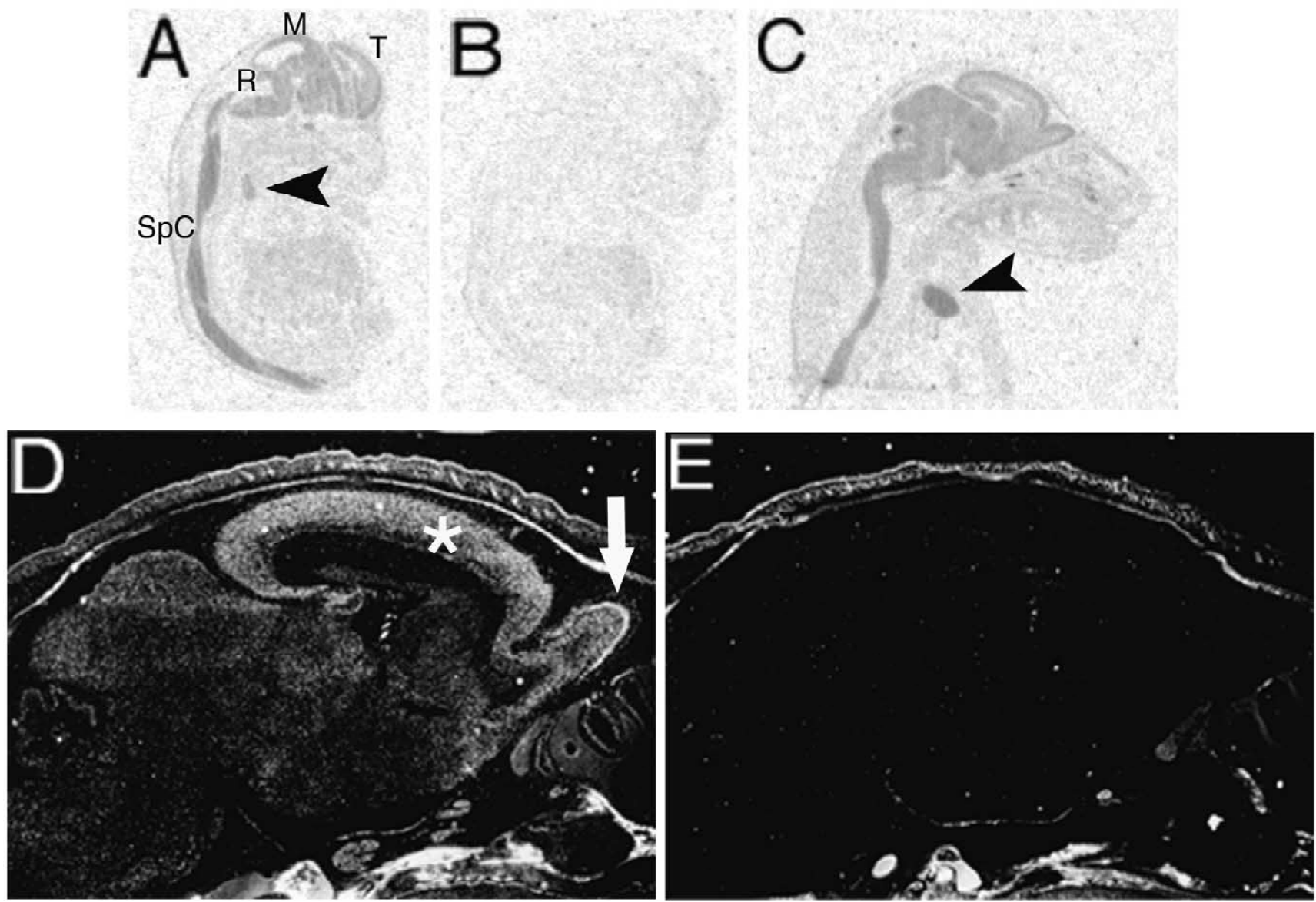

Fig. 4. In situ hybridization histochemical analysis of ARHGAP4 gene expression in the developing rat nervous system. Autoradiograms of ARHGAP4 gene expression detected with ${ }^{35}$ S-UTP-labeled probe 1 in mid-sagittal sections taken from E18 (A, B), E21 (C), and postnatal day 1 (D, E) rats. Expression is evident throughout the neuraxis ( T, telencephalon; M, midbrain; R, rhombencephalon; SpC, spinal cord; asterisk, neocortex; arrow, olfactory bulb). The position of developing thymus is also indicated (arrowhead). Panels B and E show labeling of adjacent sections from the E18 and postnatal day 1 brains, respectively, with the control sense probe 1 . 


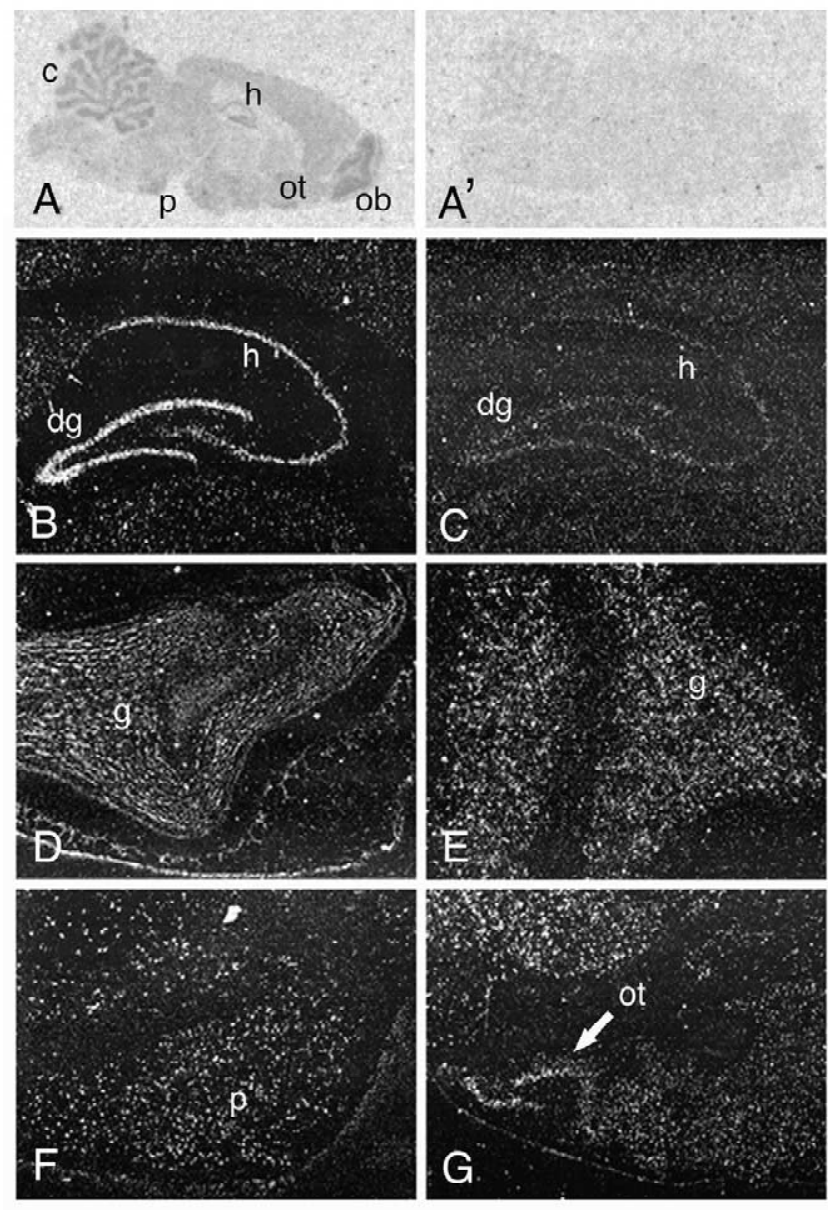

Fig. 5. In situ hybridization histochemistry of ARHGAP4 expression in adult rat brain. Phosphorimages of ARHGAP4 expression detected with ${ }^{35} \mathrm{~S}$-UTP-labeled antisense (A) and control sense (A') probe 2 in sagittal sections of adult rat brain. Darkfield micrographs of ARHGAP4 mRNA expression hybridized with probe 2 in the hippocampus (B), olfactory bulb (D), cerebellum (E), pontine nuclei (F), and olfactory tubercle (G). (C), Hybridization with the control sense riboprobe in the hippocampus. Abbreviations: c, cerebellum; dg, dentate gyrus; g, granule cells; h, hippocampus; ob, olfactory bulb; ot, olfactory tubercle; $\mathrm{p}$, pontine nuclei.

drug that interferes with GTP-loading of ARF1 GTPase, which leads to the collapse of the Golgi structure and hence intracellular protein trafficking (reviewed in [13]). Following $5 \mathrm{~min}$ stimulation with $5 \mu \mathrm{g} / \mathrm{ml}$ of BFA, endogenous ARHGAP4 was no longer associated with the Golgi complex in NRK cells but became dispersed in the cytosol (data not shown). The Golgi network is centered at the microtubule organizing center (MTOC) and requires microtubules for structure and function support [13]. Accordingly, staining with an anti- $\beta$-tubulin antibody revealed microtubules concentrated and closely associated with labeling of rat ARHGAP4 protein at the Golgi complex (Fig. 6D-F). Furthermore, in the occasional NRK cell, ARHGAP4 protein was found redistributed where it no longer localized at the Golgi network but distinctly colocalized with microtubules (Fig. 6G-I). This redistribution was particularly prominent in cells undergoing mitosis (data not shown) and cytokinesis (Fig. 6J-L). Neuronal- like PC12 cells undergoing differentiation in the presence of NGF revealed ARHGAP4 expression perinuclearly and in the terminals of extending neurites (Fig. 6M). Perinuclear colocalization with tubulin was evident but extensive overlapping expression was not observed at the ends of the neurites (Fig. 6N). Subcellular fractionation of NRK protein lysates confirmed ARHGAP4's predominant association with the particulate, insoluble fraction, whereas only low levels of ARHGAP4 protein were detected in the soluble cytosol component (data not shown).

\subsection{Immunoblot analyses}

To further confirm that the anti-ARHGAP4 antibody detected ARHGAP4 expression specifically and that ARHAGAP4 protein associated with insoluble proteins such as organelles and cytoskeletal proteins, an immunoblot comparing overexpressed, tagged and endogenous ARHGAP4 proteins in fractionated protein samples was performed. ARHGAP4 fused to a PKC $\epsilon$-specific epitope and under the control of a metallothionine promoter (p€MTH-ARHGAP4) was transfected into NIH 3T3 cells. p€MTH-ARHGAP4 expression was induced following the addition of zinc acetate. Protein cell lysates were subcellularly fractionated into soluble cytosol components (supernatant fraction) and insoluble particulate components (pellet fraction) and an immunoblot was performed using anti-PKC $\epsilon$ or anti-ARHGAP4 antibodies (Fig. 7A). In the blot probed with the anti-PKC $\epsilon$ antibody (left panel), a 94-kDA band representing endogenous PKC $\epsilon$ in the soluble supernatant fractions of both untransfected and transfected NIH 3T3 was detected. Only the insoluble pellet fraction from the transfected NIH 3T3 cells revealed a larger isoform of approximately $130 \mathrm{kDa}$, which presumably represents PKC $\epsilon$-tagged ARHGAP4. To confirm that this band is the ARHGAP4 fusion protein, extracts from the same NIH 3 T3 fractions were immunoblotted with the anti-ARHGAP4 antibody (right panel). The same $130 \mathrm{kDa}$ band was revealed in the insoluble pellet fraction from the transfected NIH 3T3 cells while an additional 120 $\mathrm{kDa}$ band appeared predominantly in both the insoluble pellet fractions from the untransfected and transfected NIH 3T3 cells. These bands represent endogenous ARHGAP4. Furthermore, immunofluorescence analysis with the antiPKC $\epsilon$ antibody of NIH 3T3 cells transiently transfected with $\mathrm{p} \in \mathrm{MTH}-\mathrm{ARHGAP} 4$ revealed predominant perinuclear staining with greater intensity around the Golgi complex (Fig. 7B).

An extensive analysis of endogenous ARHGAP4 protein expression in various rat tissues was next performed. An immunoblot analysis using anti-ARHGAP4 antibodies revealed ARHGAP4 protein predominantly as a $120-\mathrm{kDa}$ protein in numerous tissues and cell extracts (Fig. 7C). In tissues such as kidney, thymus and spleen, a protein doublet was evident while smaller isoforms, particularly in the brain tissues and rat neuronal PC12 cell extracts, were also observed and may represent modified and spliced 

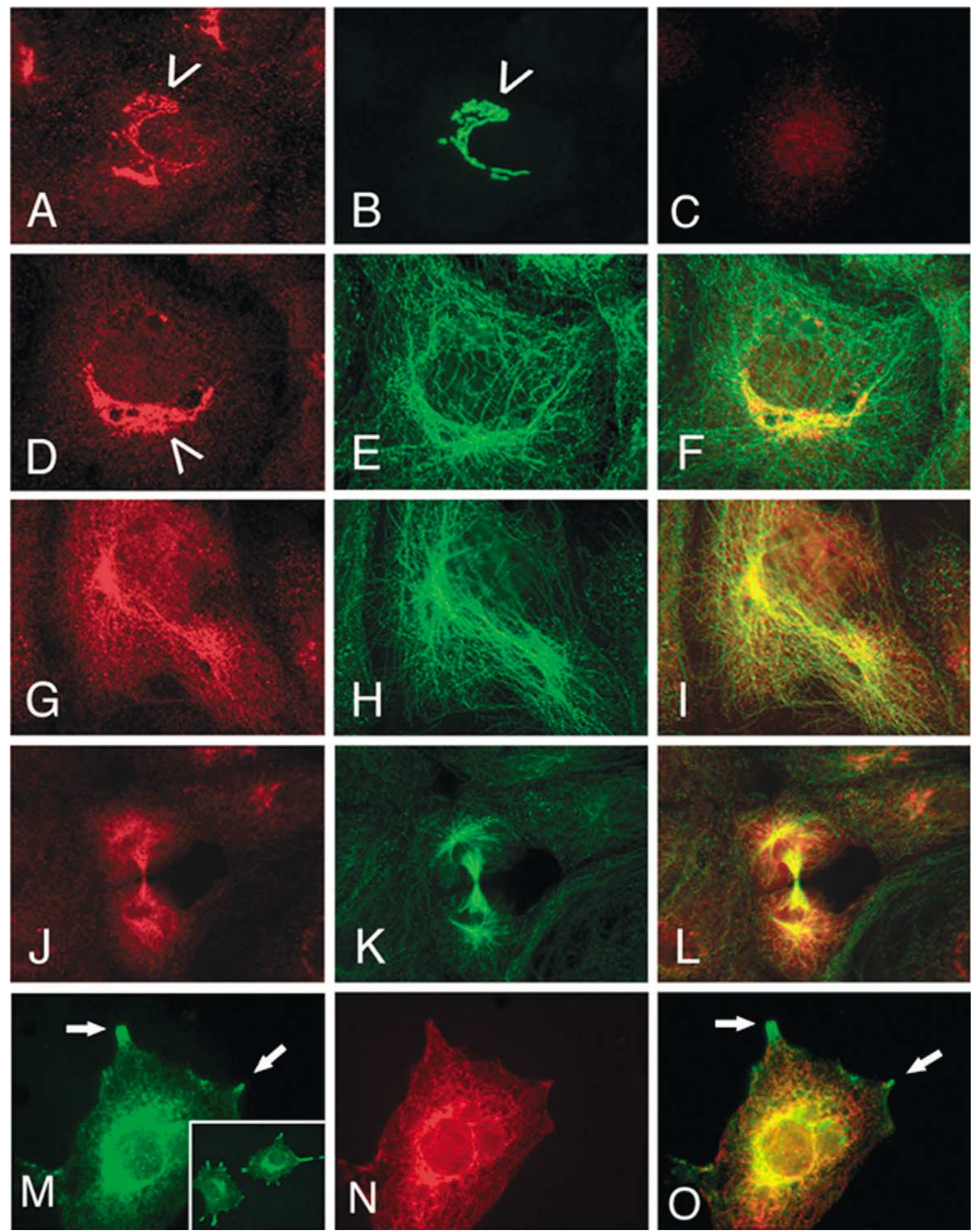

Fig. 6. Endogenous subcellular localization of ARHGAP4. Endogenous ARHGAP4 expression in rat NRK epithelial cells (A, D, G, and J) and PC12 cells (M) following immunofluorescent staining with a rabbit polyclonal anti-ARHGAP4 antibody. (B), The Golgi network (arrowheads) is identified following transfection of a construct expressing the Golgi-specific enzyme, $\beta 1$,4-galactosyltransferase fused with GFP. (C) Staining with rabbit preimmune serum. $\beta$-tubulin expression (E, H, K and N), and overlapping expression of ARHGAP4 with $\beta$-tubulin is indicated in normal NRK cells (F and I) and those undergoing cytokinesis (L), and also in PC12 cells following 2 day stimulation with $100 \mathrm{ng} / \mathrm{ml} \mathrm{NGF} \mathrm{(O).} \mathrm{(M),} \mathrm{Localization} \mathrm{of} \mathrm{ARHGAP4} \mathrm{at} \mathrm{the} \mathrm{tips} \mathrm{of}$ extending PC12 neurites (arrows; and see inset).

variants of rat ARHGAP4 protein. The possibility of spliced variants is in keeping with the multiple transcripts revealed by the Northern analysis. Although moderate
mRNA levels in the developing and adult nervous system were detected, only low levels of full-length ARHGAP4 protein were detected, especially in fetal brain extracts, and 


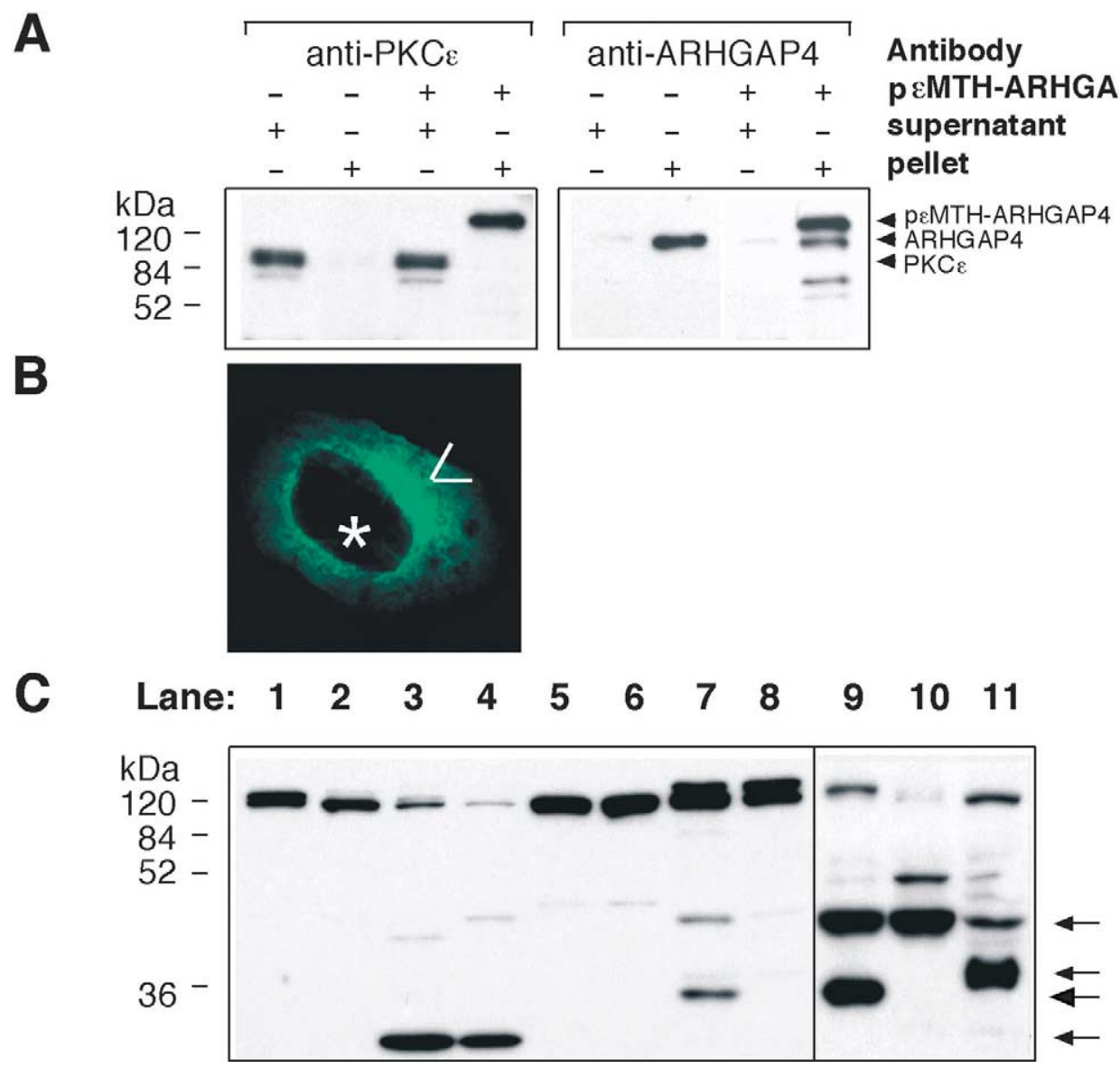

Fig. 7. Immunoblot analysis of overexpressed tagged and endogenous ARHGAP4 protein expression. (A) Fractionated protein lysates from untransfected NIH $3 \mathrm{~T} 3$ cells or cells transfected with PKC $\epsilon$-tagged ARHGAP4 (p€MTH-ARHGAP4) immunoblotted with anti-PKC $\epsilon$ (left panel) and anti-ARHGAP4 (right panel) antibodies and visualised with HRP-conjugated anti-rabbit IgG antibody. (B) Immunofluorescent staining with anti-PKC $\epsilon$ antibody of NIH $3 \mathrm{~T} 3$ cells transiently transfected with p€MTH-ARHGAP4. Asterisk and arrowhead denotes nucleus and Golgi complex, respectively. (C) Thirty (lanes 1-8) or sixty (lanes 9-11) micrograms of total protein lysates extracted from rat tissues or cell lines were immunoblotted with anti-ARHGAP4 antibody. Smaller ARHGAP4 isoforms are indicated (arrows). Lanes: 1, kidney; 2, heart; 3, lung; 4, liver; 5, small intestine; 6, large intestine; 7, spleen; 8, thymus; 9 , brain; 10, fetal brain (E18); 11, rat PC12 cells.

despite high expression of ARHGAP4 mRNA in spleen and thymus, ARHGAP4 protein levels in these tissues were comparable to other tissues such as kidney and intestinal tissues. Pre-absorption of the antibody with an excess of the peptide used for the rabbit's immunization prevented specific labeling of the antibody (data not shown).

\subsection{Immunofluorescence analyses}

Immunofluorescence analysis of ARHGAP4 protein in adult rat brain revealed staining in restricted regions (Fig. 8). Rat ARHGAP4 labeling was evident in neuronal fibers within the stratum lucidem of the CA2-CA3 region of the hippocampus (Fig. 8A), but not significantly in the cell bodies of the pyramidal cells where ARHGAP4 mRNA expression was detected (Fig. 4B). Low levels of
ARHGAP4 staining were also evident in the molecular layer of the dentate gyrus (data not shown). The granular layer of the cerebellum revealed ARHGAP4 labeling; however, no staining in the Purkinje cells was evident (Fig. 8C). In specific ventral regions of the brainstem and striatum (Fig. 8D-F), ARHGAP4 protein was primarily detected in neuronal fibers. Pre-absorption of the primary antibody with the corresponding peptide prevented any specific labeling (Fig. 8B).

\section{Discussion}

This study expands the analysis of ARHGAP4, a relatively uncharacterised member of the RhoGAP family. We show that the rat and human ARHGAP4 and V2R gene loci are conserved as the two genes are closely linked and orientated towards each other on complementary DNA 


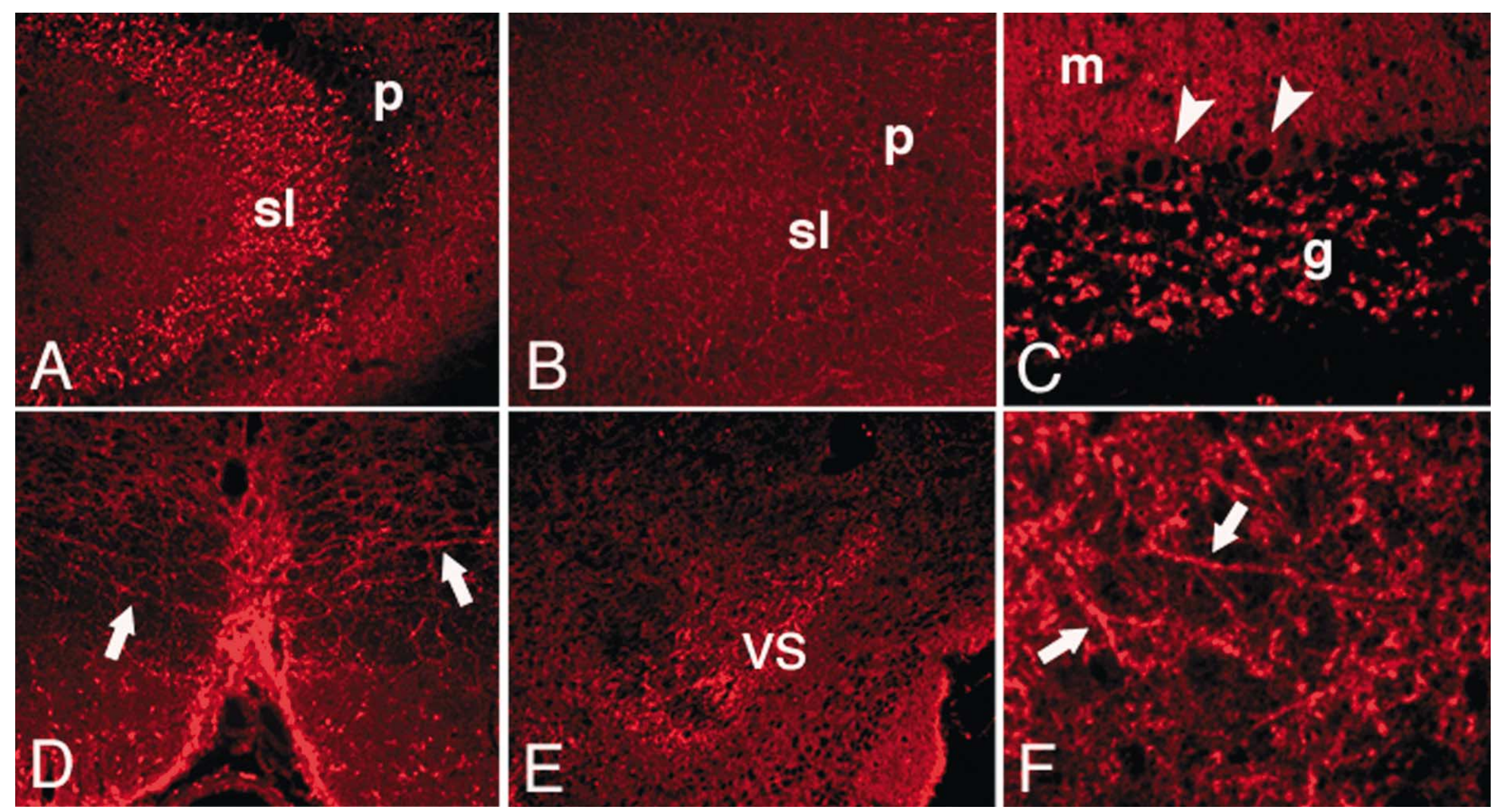

Fig. 8. Immunostaining of ARHGAP4 in adult rat brain. ARHGAP4 protein expression was detected using the anti-ARHGAP4 antibody on coronal sections of the hippocampus (A), cerebellum (C), brainstem (D), ventral striatum (E and F). Immunostaining of ARHGAP4 expression in the hippocampus following preabsorption of the anti-ARHGAP4 antibody with the peptide used for immunization (B). Arrowheads and arrows indicate Purkinje cells and neuronal fibers, respectively. Abbreviations: g, granule layer; m, molecular layer; p, pyramidal cells; sl, stratum lucidem; vs, ventral striatum. Magnification: $10 \times, \mathrm{A}, \mathrm{B}, \mathrm{D}$ and $\mathrm{E} ; 25 \times, \mathrm{C} ; \mathrm{F}, 40 \times$. 
strands in both species. However, the rat ARHGAP4 gene appears different from its human counterpart in that it transcribes multiple transcripts including an $11-\mathrm{kb}$ species. This large transcript overlaps the rat V2R gene locus in an antisense direction and hence raises several discussion points. RACE analysis revealed a $3.2-\mathrm{kb}$ cDNA derived from rat thymus RNA although a $6.4-\mathrm{kb}$ cDNA was also isolated from a rat spleen cDNA library. This suggests a large 3' untranslated region that overlaps the V2R gene and may be utilised alternately by the rat ARHGAP4 gene. The sequence of the human Xq28 V2R/ARHGAP4 locus ${ }^{2}$ reveals human ARHGAP4 as a complex gene containing 22 exons and the rat ortholog is likely to be similar. If so, then numerous intron/exon boundaries with alternate or incomplete splicing may account for the multiple ARHGAP4 transcripts detected. As we have demonstrated a sense/antisense overlap between rat ARHGAP4's $11 \mathrm{~kb}$ transcript and V2R's transcriptional unit, it would also be interesting to determine whether RNA-RNA duplexes form between the ARHGAP4 and V2R transcripts and affect rat V2R's translation. Close linkage and overlapping sense/antisense transcripts expressed in the same cell-type from two unrelated genes have been described before but it is not clear if they impact on each other's protein levels [27]. Interestingly, there are conflicting reports regarding the extent of rat V2R's gene expression in the brain, and ARHGAP4's $11 \mathrm{~kb}$ transcript could contribute to these discrepancies. Exclusive V2R gene expression in the kidney has been described following Northern, in situ hybridization and receptor-binding studies [28,39,43]. In contrast, there are also reports of V2R mRNA expression in the brain and inner ear of rats as detected by reverse transcriptase PCR and in situ hybridization [10,20,22,24]. However, when examining the techniques adopted in these latter studies, double-stranded DNA probes were used for the in situ hybridization analyses, and random hexamer or oligo-dT were used as primers for the reverse transcriptase reactions rather than gene-specific oligonucleotides. These approaches do not differentiate between RNA transcripts potentially expressed from either DNA strand; hence, the expression of rat ARHGAP4 may have been inadvertently detected and ascribed to rat V2R transcripts.

More importantly, ARHGAP4 regulates Rac1, Cdc42 and RhoA activities in vitro and localizes in NRK and PC12 cells primarily to the Golgi complex, microtubules and terminal ends of differentiating neurites. Western blotting also demonstrated rat ARHGAP4 protein in multiple tissues, including the hematopoietic and nervous systems, whereas immunostaining analysis confirmed ARHGAP4 expression in differentiated neuronal fibers in specific regions of the adult rat brain. Finally, ARHGAP4 possesses other protein-protein interaction domains: $\mathrm{FCH}$, SH3, and leucine zipper motifs. Together, these data suggest that ARHGAP4 may play multiple roles in intracellular signaling, membrane trafficking, cell mitosis, motility and polarity, and neuronal development and function via its control of Rho GTPases and perhaps of other molecules.

ARHGAP4's LZ motif in mammalian cells demonstrates the ability of ARHGAP4 to form homodimers and possibly heterodimers with other signaling molecules. As the LZ motif lies within the GAP domain, it may be required for effective interaction of ARHGAP4 with GTPases or dimerization may impede the ability of ARHGAP4 to behave as a GAP. It, in fact, may be the former as certain Rho-interacting targets such as protein kinase $\mathrm{N}$, rhophilin, and the myosin-binding subunit of myosin phosphatase also contain LZ sequences (reviewed in [21]). The presence of the SH3 domain suggests that ARHGAP4 is able to interact with proline-rich molecules. Indeed, such proteins were isolated following a yeast two-hybrid screen of a rat brain cDNA library using the COOH-terminal half of rat ARHGAP4 as bait (V.F. and S.Y., unpublished observations). One of these proteins was Dendrin, a sleepmodulated protein expressed in the dendrites of hippocampal and forebrain neurons of rats [19,33]. It is also of note that the FCH domain in ARHGAP4 demonstrates homology to CIP-4, a Cdc42-binding protein that is regarded as a member of a new class of Cdc42-effector molecules [2]. The significance of the $\mathrm{FCH}$ domain is currently unknown although recently the $\mathrm{NH}_{2}$-terminus of CIP-4, which includes this domain, was shown to mediate the binding of the Wiskott-Aldrich syndrome protein (WASP) to microtubules [51]. As both $\mathrm{Cdc} 42$ and RhoB localize to the Golgi network [14,32], they are logically potential targets for ARHGAP4, and while Rac1 can bind microtubulin in vitro [5], its physiological colocalization to this cytoskeletal protein has yet to be demonstrated. Rather, effector and interacting molecules such as CIP-4/WASP and several GEFs appear to provide the intermediary linkage for the association of Cdc42, Rac1 and RhoA to microtubules $[17,44,51,55]$. Rho also helps stabilize microtubulin formation [12,40] while Cdc42 regulates MTOC orientation [41], both via effector molecules. ARHGAP4 may behave similarly and may be the first RhoGAP recognized to associate with microtubulin.

The detection of ARHGAP4 at the tips of differentiating neurites of PC12 cells without significant colocalization with tubulin suggests that it may be involved in axon and dendritic growth, a function that more intimately involves actin (reviewed by [29]). Indeed, very recent work has identified ARHGAP4 protein in the mossy fibers of the stratum lucidem and found to inhibit their outgrowth [31]. However, the presence of ARHGAP4 in neuronal fibers in the adult brain again suggests an association with microtubulin. Tubulin provides structural and functional support for dendrites, axons and the axonal transport of cytoplasmic components and has developmental roles in neuronal growth cone motility, migration and polarity $[3,4,50]$. One of the roles of $\mathrm{Cdc} 42$ is to control cell polarity through the reorientation of the Golgi apparatus. This has been demonstrated in fibroblasts, macrophages, $\mathrm{T}$ 
cells, and astrocytes [1,15,35,49]. Although the precise role of $\mathrm{Cdc} 42$ in neuronal polarity and migration remains to be established, a recent report identifies a new class of highly homologous GAPs to ARHGAP4. These slit-robo (sr) GAPs are implicated with Cdc42 in Slit signaling. Slit is an extracellular guide for neuronal and leukocyte migration, and transmits its repulsive cues through its transmembrane receptor Roundabout (robo) and the interacting srGAPs [56]. Although ARHGAP4 regulates multiple Rho GTPases in vitro, further studies in different cell systems involving the overexpression of Rho GTPase activated mutants to look for endogenous ARHGAP4's recruitment, and/or the overexpression of ARHGAP4 to inhibit these mutants' activities should help define which GTPase ARHGAP4 targets in vivo.

\section{Acknowledgements}

The pGEX-2T-RhoA, pGEX-4T-3-Rac1 and pGEX-2TCdc42, and peMTH plasmids were provided by Drs. G. Bokoch (Scripps Research Institute, La Jolla, CA) and W. Anderson (NCI, Bethesda, MD), respectively. We thank Drs. D. Segal and P. Randazzo for their helpful comments and advice, and R. Dreyfuss for photography.

\section{References}

[1] W.E. Allen, D. Zicha, A.J. Ridley, G.E. Jones, A role for Cdc42 in macrophage chemotaxis, J. Cell Biol. 141 (1998) 1147-1157.

[2] P. Aspenstrom, A Cdc42 target protein with homology to the non-kinase domain of FER has a potential role in regulating the actin cytoskeleton, Curr. Biol. 7 (1997) 479-487.

[3] P.W. Baas, Microtubules and axonal growth, Curr. Opin. Cell Biol. 9 (1997) 29-36.

[4] P.W. Baas, Microtubules and neuronal polarity: lessons from mitosis, Neuron 22 (1999) 23-31.

[5] A. Best, S. Ahmed, R. Kozma, L. Lim, The Ras-related GTPase Rac1 binds tubulin, J. Biol. Chem. 271 (1996) 3756-3762.

[6] D.J. Bradley, H.C. Towle, W.S. Young 3rd, Spatial and temporal expression of alpha- and beta-thyroid hormone receptor mRNAs, including the beta 2-subtype, in the developing mammalian nervous system, J. Neurosci. 12 (1992) 2288-2302.

[7] M.R. Brouns, S.F. Matheson, K.Q. Hu, I. Delalle, V.S. Caviness, J. Silver, R.T. Bronson, J. Settleman, The adhesion signaling molecule p190 RhoGAP is required for morphogenetic processes in neural development, Development 127 (2000) 4891-4903.

[8] M.R. Brouns, S.F. Matheson, J. Settleman, p190 RhoGAP is the principal Src substrate in brain and regulates axon outgrowth, guidance and fasciculation, Nat. Cell Biol. 3 (2001) 361-367.

[9] S. Castellvi-Bel, M. Mila, Genes responsible for nonspecific mental retardation, Mol. Genet. Metab. 72 (2001) 104-108.

[10] Q. Chen, S.S. Schreiber, R.D. Brinton, Vasopressin and oxytocin receptor mRNA expression during rat telencephalon development, Neuropeptides 34 (2000) 173-180.

[11] N.B. Cole, C.L. Smith, N. Sciaky, M. Terasaki, M. Edidin, J. Lippincott-Schwartz, Diffusional mobility of Golgi proteins in membranes of living cells, Science 273 (1996) 797-801.

[12] T.A. Cook, T. Nagasaki, G.G. Gundersen, Rho guanosine triphos- phatase mediates the selective stabilization of microtubules induced by lysophosphatidic acid, J. Cell Biol. 141 (1998) 175-185.

[13] J.G. Donaldson, J. Lippincott-Schwartz, Sorting and signaling at the Golgi complex, Cell 101 (2000) 693-696.

[14] J.W. Erickson, C. Zhang, R.A. Kahn, T. Evans, R.A. Cerione, Mammalian Cdc42 is a brefeldin A-sensitive component of the Golgi apparatus, J. Biol. Chem. 271 (1996) 26850-26854.

[15] S. Etienne-Manneville, A. Hall, Integrin-mediated activation of Cdc42 controls cell polarity in migrating astrocytes through PKCzeta, Cell 106 (2001) 489-498.

[16] V.C. Foletta, N.L. Ostrowski, W.S. Young, 3rd, The characterization of an mRNA species transcribed from the complementary DNA strand of the V2R gene, Twenty-seventh annual meeting for the Society for Neuroscience, New Orleans, LA, 1997.

[17] J.A. Glaven, I. Whitehead, S. Bagrodia, R. Kay, R.A. Cerione, The Dbl-related protein, Lfc, localizes to microtubules and mediates the activation of Rac signaling pathways in cells, J. Biol. Chem. 274 (1999) 2279-2285.

[18] A. Harada, B. Furuta, K. Takeuchi, M. Itakura, M. Takahashi, M. Umeda, Nadrin, a novel neuron-specific GTPase-activating protein involved in regulated exocytosis, J. Biol. Chem. 275 (2000) 3688536891.

[19] A. Herb, W. Wisden, M.V. Catania, D. Marechal, A. Dresse, P.H. Seeburg, Prominent dendritic localization in forebrain neurons of a novel mRNA and its product, dendrin, Mol. Cell Neurosci. 8 (1997) $367-374$.

[20] A. Hirasawa, K. Hashimoto, G. Tsujimoto, Distribution and developmental change of vasopressin V1A and V2 receptor mRNA in rats, Eur. J. Pharmacol. 267 (1994) 71-75.

[21] K. Kaibuchi, Regulation of cytoskeleton and cell adhesion by Rho targets, Prog. Mol. Subcell. Biol. 22 (1999) 23-38.

[22] Y. Kato, N. Igarashi, A. Hirasawa, G. Tsujimoto, M. Kobayashi, Distribution and developmental changes in vasopressin V2 receptor mRNA in rat brain, Differentiation 59 (1995) 163-169.

[23] S. Kins, H. Betz, J. Kirsch, Collybistin, a newly identified brainspecific GEF, induces submembrane clustering of gephyrin, Nat. Neurosci. 3 (2000) 22-29.

[24] H. Kitano, T. Takeda, M. Suzuki, T. Kitanishi, Y. Yazawa, K. Kitajima, H. Kimura, I. Tooyama, Vasopressin and oxytocin receptor mRNAs are expressed in the rat inner ear, Neuroreport 8 (1997) 2289-2292.

[25] W.H. Landschulz, P.F. Johnson, E.Y. Adashi, B.J. Graves, S.L. McKnight, Isolation of a recombinant copy of the gene encoding C/EBP, Genes Dev. 2 (1988) 786-800.

[26] F.N. Leeuwen, H.E. Kain, R.A. Kammen, F. Michiels, O.W. Kranenburg, J.G. Collard, The guanine nucleotide exchange factor Tiam1 affects neuronal morphology; opposing roles for the small GTPases Rac and Rho, J. Cell Biol. 139 (1997) 797-807.

[27] A. Lerner, L. D'Adamio, A.C. Diener, L.K. Clayton, E.L. Reinherz, CD3 zeta/eta/theta locus is colinear with and transcribed antisense to the gene encoding the transcription factor Oct-1, J. Immunol. 151 (1993) 3152-3162.

[28] S.J. Lolait, A.M. O'Carroll, O.W. McBride, M. Konig, A. Morel, M.J. Brownstein, Cloning and characterization of a vasopressin V2 receptor and possible link to nephrogenic diabetes insipidus, Nature 357 (1992) 336-339.

[29] L. Luo, Rho GTPases in neuronal morphogenesis, Nat. Rev. Neurosci. 1 (2000) 173-180.

[30] K.F. Malik, H. Jaffe, J. Brady, W.S. Young 3rd, The class III POU factor Brn-4 interacts with other class III POU factors and the heterogeneous nuclear ribonucleoprotein U, Brain Res. Mol. Brain Res. 45 (1997) 99-107.

[31] A. Malouf, W.S. Young, 3rd, V.C. Foletta, RhoGAP C1 is present in mossy fibers in hippocampal slice cultures from neonatal rat, Thirtyfirst annual meeting for the Society for Neuroscience, 2001.

[32] D. Michaelson, J. Silletti, G. Murphy, P. D’Eustachio, M. Rush, M.R. Philips, Differential localization of Rho GTPases in live cells: 
regulation by hypervariable regions and RhoGDI binding, J. Cell Biol. 152 (2001) 111-126.

[33] M. Neuner-Jehle, J.P. Denizot, A.A. Borbely, J. Mallet, Characterization and sleep deprivation-induced expression modulation of dendrin, a novel dendritic protein in rat brain neurons, J. Neurosci. Res. 46 (1996) 138-151.

[34] M. Nishi, H. Takeshima, T. Houtani, K. Nakagawara, T. Noda, T. Sugimoto, RhoN, a novel small GTP-binding protein expressed predominantly in neurons and hepatic stellate cells, Brain Res. Mol. Brain Res. 67 (1999) 74-81.

[35] C.D. Nobes, A. Hall, Rho GTPases control polarity, protrusion, and adhesion during cell movement, J. Cell Biol. 144 (1999) 12351244.

[36] Z. Olah, C. Lehel, G. Jakab, W.B. Anderson, A cloning and epsilonepitope-tagging insert for the expression of polymerase chain reaction-generated cDNA fragments in Escherichia coli and mammalian cells, Anal. Biochem. 221 (1994) 94-102.

[37] C. Olenik, K. Aktories, D.K. Meyer, Differential expression of the small GTP-binding proteins RhoA, RhoB, Cdc42u and Cdc $42 \mathrm{~b}$ in developing rat neocortex, Brain Res. Mol. Brain Res. 70 (1999) 9-17.

[38] C. Olenik, H. Barth, I. Just, K. Aktories, D.K. Meyer, Gene expression of the small GTP-binding proteins RhoA, RhoB, Rac1, and Cdc42 in adult rat brain, Brain Res Mol. Brain Res. 52 (1997) 263-269.

[39] N.L. Ostrowski, S.J. Lolait, D.J. Bradley, A.M. O'Carroll, M.J. Brownstein, W.S. Young 3rd, Distribution of V1a and V2 vasopressin receptor messenger ribonucleic acids in rat liver, kidney, pituitary and brain, Endocrinology 131 (1992) 533-535.

[40] A.F. Palazzo, T.A. Cook, A.S. Alberts, G.G. Gundersen, mDia mediates Rho-regulated formation and orientation of stable microtubules, Nat. Cell Biol. 3 (2001) 723-729.

[41] A.F. Palazzo, H.L. Joseph, Y.J. Chen, D.L. Dujardin, A.S. Alberts, K.K. Pfister, R.B. Vallee, G.G. Gundersen, $\mathrm{Cdc} 42$, dynein, and dynactin regulate MTOC reorientation independent of Rho-regulated microtubule stabilization, Curr. Biol. 11 (2001) 1536-1541.

[42] P. Penzes, R.C. Johnson, R. Sattler, X. Zhang, R.L. Huganir, V. Kambampati, R.E. Mains, B.A. Eipper, The neuronal Rho-GEF Kalirin-7 interacts with PDZ domain-containing proteins and regulates dendritic morphogenesis, Neuron 29 (2001) 229-242.

[43] P.A. Phillips, J.M. Abrahams, J.M. Kelly, V. Mooser, D. Trinder, C.I.
Johnston, Localization of vasopressin binding sites in rat tissues using specific V1 and V2 selective ligands, Endocrinology 126 (1990) 1478-1484.

[44] Y. Ren, R. Li, Y. Zheng, H. Busch, Cloning and characterization of GEF-H1, a microtubule-associated guanine nucleotide exchange factor for Rac and Rho GTPases, J. Biol. Chem. 273 (1998) 34954-34960.

[45] A.J. Ridley, A. Hall, The small GTP-binding protein rho regulates the assembly of focal adhesions and actin stress fibers in response to growth factors, Cell 70 (1992) 389-399.

[46] T. Schoneberg, K. Pasel, V. von Baehr, A. Schulz, H.D. Volk, T. Gudermann, G. Filler, Compound deletion of the rhoGAP C1 and V2 vasopressin receptor genes in a patient with nephrogenic diabetes insipidus, Hum. Mutat. 14 (1999) 163-174.

[47] J. Settleman, R. Foster, Purification and GTPase-activating protein activity of baculovirus expressed p190, Methods Enzymol. 256 (1995) 105-113.

[48] S.M. Shamah, M.Z. Lin, J.L. Goldberg, S. Estrach, M. Sahin, L. Hu, M. Bazalakova, R.L. Neve, G. Corfas, A. Debant, M.E. Greenberg, EphA receptors regulate growth cone dynamics through the novel guanine nucleotide exchange factor ephexin, Cell 105 (2001) 233244.

[49] L. Stowers, D. Yelon, L.J. Berg, J. Chant, Regulation of the polarization of $\mathrm{T}$ cells toward antigen-presenting cells by Rasrelated GTPase CDC42, Proc. Natl. Acad. Sci. U.S.A. 92 (1995) 5027-5031.

[50] E. Tanaka, M.W. Kirschner, The role of microtubules in growth cone turning at substrate boundaries, J. Cell Biol. 128 (1995) 127-137.

[51] L. Tian, D.L. Nelson, D.M. Stewart, Cdc42-interacting protein 4 mediates binding of the Wiskott-Aldrich syndrome protein to microtubules, J. Biol. Chem. 275 (2000) 7854-7861.

[52] C. Tribioli, S. Droetto, S. Bione, G. Cesareni, M.R. Torrisi, L.V. Lotti, L. Lanfrancone, D. Toniolo, P. Pelicci, An X chromosomelinked gene encoding a protein with characteristics of a rhoGAP predominantly expressed in hematopoietic cells, Proc. Natl. Acad. Sci. U.S.A. 93 (1996) 695-699.

[53] C. Tribioli, M. Mancini, E. Plassart, S. Bione, S. Rivella, C. Sala, G. Torri, D. Toniolo, Isolation of new genes in distal Xq28: transcriptional map and identification of a human homologue of the ARD1 $\mathrm{N}$-acetyl transferase of Saccharomyces cerevisiae, Hum. Mol. Genet. 3 (1994) 1061-1067. 